\title{
The impact of housing improvement and socio-environmental factors on common childhood illnesses: a cohort study in Indigenous Australian communities
}

\author{
Ross S Bailie, Matthew Stevens, Elizabeth L McDonald
}

- Additional materials are published online only. To view these files please visit the journal online (http://jech.bmj. com/content/66/9.toc).

Menzies School of Health Research, Institute of Advanced Studies, Charles Darwin University, Darwin, Northern Territory, Australia

\section{Correspondence to} Professor Ross S Bailie, Post Office Box 41096, Casuarina, Darwin, Northern Territory 0811, Australia;

ross.bailie@menzies.edu.au

Accepted 25 May 2011 Published Online First 21 June 2011

\begin{abstract}
Background Improvements in health are an important expected outcome of many housing infrastructure programs. The authors aimed to determine if improvement in the notoriously poor housing infrastructure in Australian Indigenous communities results in reduction in common childhood illness and to identify important mediating factors in this relationship. Methods The authors conducted a prospective cohort study of 418 children aged 7 years or younger in 10 Australian Indigenous communities, which benefited most substantially from government-funded housing programs over 2004-2005. Data on functional and hygienic state of houses, reports of common childhood illness and on socio-economic conditions were collected through inspection of household infrastructure and interviews with children's carers and householders. Results After adjustment for a range of potential confounding variables, the analysis showed no consistent reduction in carers' reporting of common childhood illnesses in association with improvements in household infrastructure, either for specific illnesses or for these illnesses in general. While there was strong association between improvement in household infrastructure and improvement of hygienic condition of the house, there were only marginal improvements in crowding.
\end{abstract}

Conclusions High levels of household crowding and poor social, economic and environmental conditions in many Australian Indigenous communities appear to place major constraints on the potential for building programs to impact on the occurrence of common childhood illness. These findings reinforce the need for building programs to be supported by a range of social, behavioural and community-wide environmental interventions in order for the potential health gains of improved housing to be more fully realised.

\section{BACKGROUND}

There is mounting evidence that the focus by housing programs on infrastructure and the relative neglect of hygiene and other factors affecting the physical and social environment has failed to produce improvements in health in both the international context ${ }^{1-3}$ and in Australia. ${ }^{4-8}$ This emerging evidence is of vital importance to appropriate development of housing policy, particularly where a key objective of housing programs is to improve health outcomes-as is the case for Australian Indigenous communities. ${ }^{5} 9$
Numerous reviews have described the associations between housing conditions and child health and development. ${ }^{10-16}$ These reviews describe the complex interplay of factors influencing the associations between housing and health and the challenges of determining causality in studies of this relationship. There is some evidence from crosssectional studies in remote Indigenous communities in Australia that the functional state of household infrastructure is related to occurrence of childhood infections, but this relationship is confounded by a range of sociodemographic, psychosocial and behavioural factors. There is a need for study designs that are better able to determine causal relationships, specifically longitudinal studies that take account of the design and implementation of housing programs and the multiple confounding factors, which operate in specific contexts. ${ }^{17} 18$

Our previous report on a longitudinal analysis of remote Indigenous housing programs describes their limited community level impact on crowding, infrastructure function and hygiene. ${ }^{19}$ We collected concurrent data on health centre presentations for, and carer reports of, common childhood illnesses. This paper focuses on the impact of housing programs on the occurrence of common childhood illness as reported by the children's carers. Our focus is on five infectious conditions (skin sores, scabies, respiratory infection, diarrhoeal disease and ear infections), which occur commonly among children in these communities and which are an important threat to the general health and development of these children. ${ }^{20-28}$ We aimed to determine if improvement in housing infrastructure was associated with a reduction in carer report of these five conditions and to identify factors that mediate or modify this relationship.

\section{Study setting and intervention}

The Housing Infrastructure and Child Health (HICH) Study was conducted in 10 Northern Territory (NT) communities in which there was the greatest construction of new houses over the period 2004-2005. The communities were spread across the NT, between 1 and $500 \mathrm{~km}$ from the nearest regional town. The people living in these communities continue to be affected by the legacy of 200 years of colonial history on their lifestyles and traditional beliefs and practices. ${ }^{4-6} 20$ They generally experience poor health, educational, employment and other social outcomes ${ }^{28}$ and face 
significant geographic and other barriers to accessing essential services.

The mean population of the 10 communities was 730, with an average of 11 people per house-markedly higher than the national average of 3.5 for Indigenous households and of 2.6 for all Australian households. ${ }^{28}$ The extended nature of Indigenous families, high levels of crowding and generally poor quality of existing housing means that availability of new housing may result in a complex movement of people from pre-existing to new houses and between pre-existing houses.

There was an average of 11 (range 7-15) houses constructed in each of the 10 communities over the course of the study, with no concurrent renovation programs or hygiene promotion activities. The housing design standards were significantly more rigorous than standards applied in these communities over past decades. ${ }^{29}$ The study setting and intervention are described in more detail elsewhere. ${ }^{17} 1930$

\section{METHODS}

Ethics approval was obtained from the Human Research Ethics Committees in the Top End and Central regions of the NT, and formal agreements to participate were signed by peak organisations in each of the study communities. Informed consent to participate in the study was obtained from householders and children's carers prior to the conduct of household surveys and interviews.

\section{Study design}

The analysis reported here is one part of the broader $\mathrm{HICH}$ Study and involves a prospective cohort of children aged younger than 7 years who were resident in these communities at the time of commencement of the study. Eligible children were identified from community population lists held by the health centre in each community and discussion with knowledgeable community members about the resident status of each child. Details of the conceptual framework and methods used in the $\mathrm{HICH}$ Study, including community engagement, development of survey forms, obtaining informed consent, conduct of the fieldwork and community feedback, are described in detail in previous publications. ${ }^{17} 1930$

\section{Data collection methods}

The data collection methods relevant to this paper include (1) structured interviews with the main carer of each child aged 7 years or younger (the person considered by household residents to have primary responsibility for the care of the child and to be the primary decision maker regarding the child's care) and with the main householder (the person considered by household residents to have primary responsibility for the running of the house and to be the primary decision maker on household matters) and (2) surveys of the functional and hygienic state of the infrastructure in these houses. Local community residents were employed to work with survey teams and played a key role in the conduct of the fieldwork.

The baseline householder interviews and infrastructure surveys were completed on average 6 months (range 1-18) prior to occupation of new houses in each community. Follow-up interviews and surveys were completed on average 10 months (range 7-12) after occupation of new houses. The variation between communities in the timing of surveys in relation to occupation of new houses resulted from uncertainties (and in some cases significant delays) in the completion date of building programs, the need to arrange surveys at a time that suited key community-based and other organisations involved in supporting the implementation of the study, seasonal influences on access to communities (eg, seasonal flooding) and capacity within the survey team.

\section{Outcome measures}

Carer report of child health in the 2 weeks preceding the interview was collected for the following health outcomes at baseline and follow-up: (1) skin infection with no scabies, (2) scabies with or without skin infection, (3) respiratory infection, (4) gastroenteritis and (5) ear infection. We created an additional outcome measure of carer report of any of these illnesses (referred to as 'any illness' hereafter) in the 2 weeks preceding the interview. For each outcome, a dichotomous variable was created reflecting if (1) there was a carer report that the child had an illness at baseline and no illness at follow-up (defined as a 'positive change health outcome') or (2) any other pattern of report of illness at baseline and follow-up.

\section{Exposure measures}

\section{Primary exposure measures}

The infrastructure surveys involved an inspection (and where appropriate, testing) of the functional state of each house in relation to the infrastructure required to conduct a set of 'Healthy Living Practices' (HLPs). ${ }^{31} 32$ Examples of HLPs include washing people, washing clothes, and preparing and cooking food. The survey process and the two methods used to score house infrastructure function and the repeatability of these methods have been described previously. ${ }^{19} 30$ In brief, for the first method, a score of 1 (good) to 7 (poor) was assigned to each house for 13 surveyor rated HLPs and an overall house score. The score was assigned by surveyors who visually inspected the house to determine the functional state of the infrastructure required to carry out the HLP and is referred to as the Surveyor Function Score (SFS). For the second method, the surveyors assigned a pass/fail score to the functional state of the infrastructure items required for eight specific HLPs, which were suited to this pass/fail type of assessment (five of the HLPs were not suited to pass/fail assessment). These scores were then used to create a single measure of the number of HLPs that the house failed, with a score of 0 indicating all eight HLPs were 'passed' and a score of 8 indicating all eight HLPs were 'failed'. Both of these scoring methods were used at baseline and follow-up surveys of houses where study children were resident. Thus, at both baseline and follow-up, we have two measures of overall functional state of infrastructure (overall SFS measured on a 1-7 scale and number of failed HLPs (FHLPs) measured on a 1-8 scale) and measures of the functional state of 13 specific HLPs (each measured on a 1-7 scale).

In order to derive measures of change in infrastructure function between houses where study children were resident at baseline and follow-up, scores from the follow-up survey for each of the scores described above were subtracted from the scores at baseline. For each child, the change in infrastructure function between baseline and follow-up were categorised as (1) improved by two or more points; (2) limited (one point) or no change and (3) deteriorated by two or more points.

\section{Secondary exposure variables}

To assess the hygienic condition of houses, surveyors were required to determine a Surveyor Condition Score (SCS) for the hygienic condition of the areas or infrastructure items required for specific HLPs and for the overall house, again using a 7-point Likert scale. Measures of change in hygienic condition were 
calculated as described for measures of change in infrastructure function above.

The interviews with carers and householders at baseline and follow-up covered a range of sociodemographic, socio-economic, psychosocial and health behaviour variables (see supplementary file 1). Among these variables, for those where change over the course of the study might be an important confounding factor (eg, household crowding), we calculated measures of change between baseline and follow-up.

\section{Statistical methods}

The analysis follows a hierarchical approach to modelling of positive change for each outcome. For report of each or any illness, the outcome variable is dichotomous (positive change health outcome vs other) and is therefore suited to logistic regression modelling. Confidence intervals (CIs) in all analyses were adjusted for clustering of children in houses and communities.

The logistic regression analysis involved the following steps for each of the five child health outcomes. First, bivariate associations with the outcome measures were assessed for all primary and secondary exposure variables. All primary and secondary exposure variables showing a moderate $(p \leq 0.10)$ association with the positive change health outcome were then retained for the next stage of analysis. Second, for each domain of the study conceptual framework, ${ }^{17}$ variables retained from the first stage were entered simultaneously into a model and backward elimination carried out until only significant variables $(p \leq 0.05)$ were retained. Third, all variables retained at stage two were entered into a single model and backward elimination again carried out until all variables in the model remained significant $(p \leq 0.05)$. Because of potential colinearity between the different measures of infrastructure function, these measures were analysed separately for each of the second and third steps above.

To examine the possibility that baseline levels of the primary exposure variables affected any observed associations, the analyses for the primary exposure variables were repeated stratifying by scores $<4$ and $\geq 4$. Because of the potential for modification of the impact of improved infrastructure by level of crowding or by changes in crowding over the course of the study, we stratified by number of adults in the house at baseline and by change in persons per bedroom (PPB) (using the median for each measure). Finally, plausible first order interactions were tested, and if significant, the interaction contrasts were generated and included in the multivariate models.

We used multinomial logit regression models to examine associations between the key exposure variables of change in SFS, change in SCS and change in crowding.

All analyses were carried out using Stata V.10.1@ (Stata Corp serial number 1910541057).

\section{RESULTS}

Of 618 children included in the baseline survey, 418 (68\%) were followed up. These 418 children comprise the cohort, which is the focus of the analysis presented in this paper. The most common reason for loss to follow-up was that children and/or their families had moved temporarily or permanently to another community. About half of the children were aged between 3 and 7 years at baseline and about a third were between 1 and 3 years, with the rest $<1$ year. There were no significant differences in key sociodemographic variables at baseline between children in the cohort and those surveyed at baseline only, except in educational level of carer (carers of children in the cohort tended to have completed more years of schooling compared with those at baseline only).
The 418 children in the cohort were living in 185 houses at baseline and 208 houses at follow-up. Eighty-two percent of the cohort had the same carer at follow-up, $73 \%$ had the same householder and $60 \%$ were living in the same house. There were complete data for $75 \%$ of children for the FHLP measure, $83 \%$ for the SFS and SCS measures and $72 \%$ for the crowding measure. The most common reason for the missing data was not being able to access relevant parts of the house (due to sensitivities of some residents in providing access and requirement of surveyors to respect the privacy concerns of residents) or not being able to obtain counts of persons staying in the house (figure 1) (due to inability of some key informants to provide data on counts).

\section{Summary findings for primary outcome}

There was little difference in the proportion of children with a report of illness between those in the cohort and those surveyed at baseline only (table 1). Between $12 \%$ and $22 \%$ of children included in the cohort had a 'positive change health outcome' for various illnesses.

\section{Summary findings for primary exposure}

About $16 \%$ of children in the cohort had missing data for one or more of the SFS items, and 25\% were missing some of the data required to calculate the overall FHLP score (table 2). The overall SFS showed an improvement of two or more points for $25 \%$ of children, and the overall FHLP showed this level of improvement for $38 \%$ of children. For most specific SFS measures, there was an improvement of two or more points for between $14 \%$ and $29 \%$ of children, with the exception being 'remove rubbish', which showed this level of improvement for only about $6 \%$ of children.

\section{Unadjusted bivariate associations for primary outcome and primary exposure variables}

Unadjusted analysis (table 2) showed improvement in overall SFS, overall FHLP and 'remove rubbish' SFS to be associated with a positive change health outcome in report of scabies. On bivariate analysis, this was the only significant association between a positive change health outcome on carer report and improvement in infrastructure. There were no significant associations between any of the primary exposure variables and positive change in health outcome for any illness or skin infection and some counterintuitive associations between measures of change in infrastructure function and positive change health outcomes for carer report of gastroenteritis and ear infection.

The unadjusted stratified analysis for associations between change in infrastructure and positive change in health outcomes (see supplementary file 2) shows that for children who experienced a greater reduction in crowding, there was a more consistent pattern of associations (and generally larger effect size) between improvement in infrastructure and positive change in health outcomes: improvement in overall SFS, overall FHLP, 'wash clothes and bedding' SFS, 'prepare and store food SFS, remove human waste SFS', 'remove rubbish' SFS and 'control mould' SFS were associated with a positive change in report of scabies; improvement in 'remove rubbish' SFS was associated with a positive change in report of skin infection. However, there were also some counterintuitive associations in this stratified analysis. In contrast to stratification by different levels of change in crowding, stratification by different levels of change in hygienic condition (as measured by overall SCS), by number of adults in the house at baseline or by state of infrastructure function at baseline did not provide a clearer pattern of 
Figure 1 Number of households and children at baseline and follow up, and features of cohort (including number of children with complete data).
Numbers of eligible households at baseline

326 houses with children aged 7 years or less

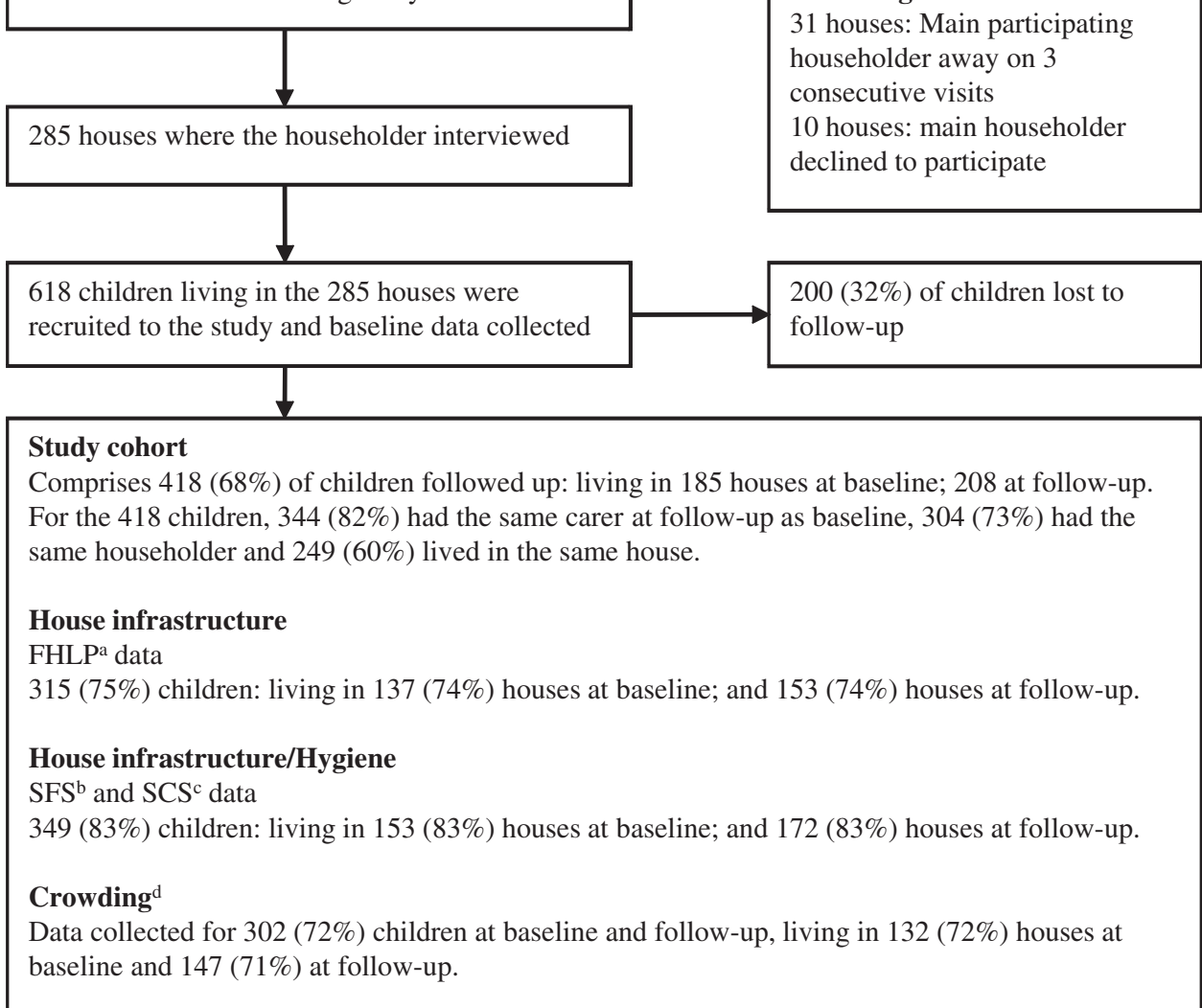

${ }^{a}$ FHLP $=$ Failed Healthy Living Practices, ${ }^{\mathrm{b}}$ SFS $=$ Surveyor Function Score,${ }^{\mathrm{c}}$ Surveyor Condition Score, ${ }^{\mathrm{d}}$ Crowding $=$ PPB

Table 1 Carer's report of childhood illness in the preceding 2 weeks for all children at baseline and for children in the study cohort, and change in report of illness between baseline and follow-up

\begin{tabular}{|c|c|c|c|c|c|c|}
\hline & $\begin{array}{l}\text { Any illness } †, \\
\text { n (\%) }\end{array}$ & $\begin{array}{l}\text { Skin infection } \\
\text { (no scabies), } \\
\text { n (\%) }\end{array}$ & $\begin{array}{l}\text { Scabies (with or } \\
\text { without skin } \\
\text { infection), } \\
\text { n (\%) }\end{array}$ & $\begin{array}{l}\text { Respiratory infection, } \\
\text { n (\%) }\end{array}$ & $\begin{array}{l}\text { Gastroenteritis, } \\
\text { n (\%) }\end{array}$ & $\begin{array}{l}\text { Ear infection, } \\
\text { n (\%) }\end{array}$ \\
\hline $\begin{array}{l}\text { Report 'no illness' at } \\
\text { baseline (all children at } \\
\text { baseline, } n=618 \text { ) }\end{array}$ & $223(36.1)$ & $496(80.3)$ & $512(82.9)$ & $440(71.2)$ & $429(69.4)$ & $445(72.0)$ \\
\hline $\begin{array}{l}\text { Report 'no illness' at } \\
\text { baseline (cohort children } \\
\text { only, } n=418 \text { ) }\end{array}$ & $152(36.4)$ & $343(82.1)$ & $342(81.8)$ & $297(71.1)$ & $278(66.5)^{*}$ & $297(71.1)$ \\
\hline \multicolumn{7}{|l|}{ For cohort children only: } \\
\hline $\begin{array}{l}\text { Report 'yes' at baseline, } \\
\text { 'no' at follow-up }\end{array}$ & $86(20.6)$ & $53(12.7)$ & $65(15.6)$ & $80(19.1)$ & $92(22.0)$ & $58(13.9)$ \\
\hline $\begin{array}{l}\text { Report 'no' at baseline, } \\
\text { 'no' at follow-up }\end{array}$ & $64(15.3)$ & $259(62.0)$ & $306(73.2)$ & $224(53.6)$ & $231(55.3)$ & $235(56.2)$ \\
\hline $\begin{array}{l}\text { Report 'no' at baseline, } \\
\text { 'yes' at follow-up }\end{array}$ & $88(21.1)$ & $84(20.1)$ & $36(8.6)$ & $73(17.5)$ & $47(11.2)$ & $62(14.8)$ \\
\hline $\begin{array}{l}\text { Report 'yes' at baseline, } \\
\text { 'yes' at follow-up }\end{array}$ & $180(43.1)$ & $22(5.3)$ & $11(2.6)$ & $41(9.8)$ & 48 (11.5) & $63(15.1)$ \\
\hline
\end{tabular}

between variables (from none to up to $28 \%$ of children), with variables relating to carer psychosocial health and to health behaviour and hygiene having the most missing data.

Notable changes between secondary exposure variables at baseline and at follow-up included that $18 \%$ of children had a different main carer at follow-up; almost $20 \%$ of children not attending childcare at baseline were attending childcare at

baseline or where relevant, a change in the exposure between

baseline and follow-up. The amount of missing data differed 


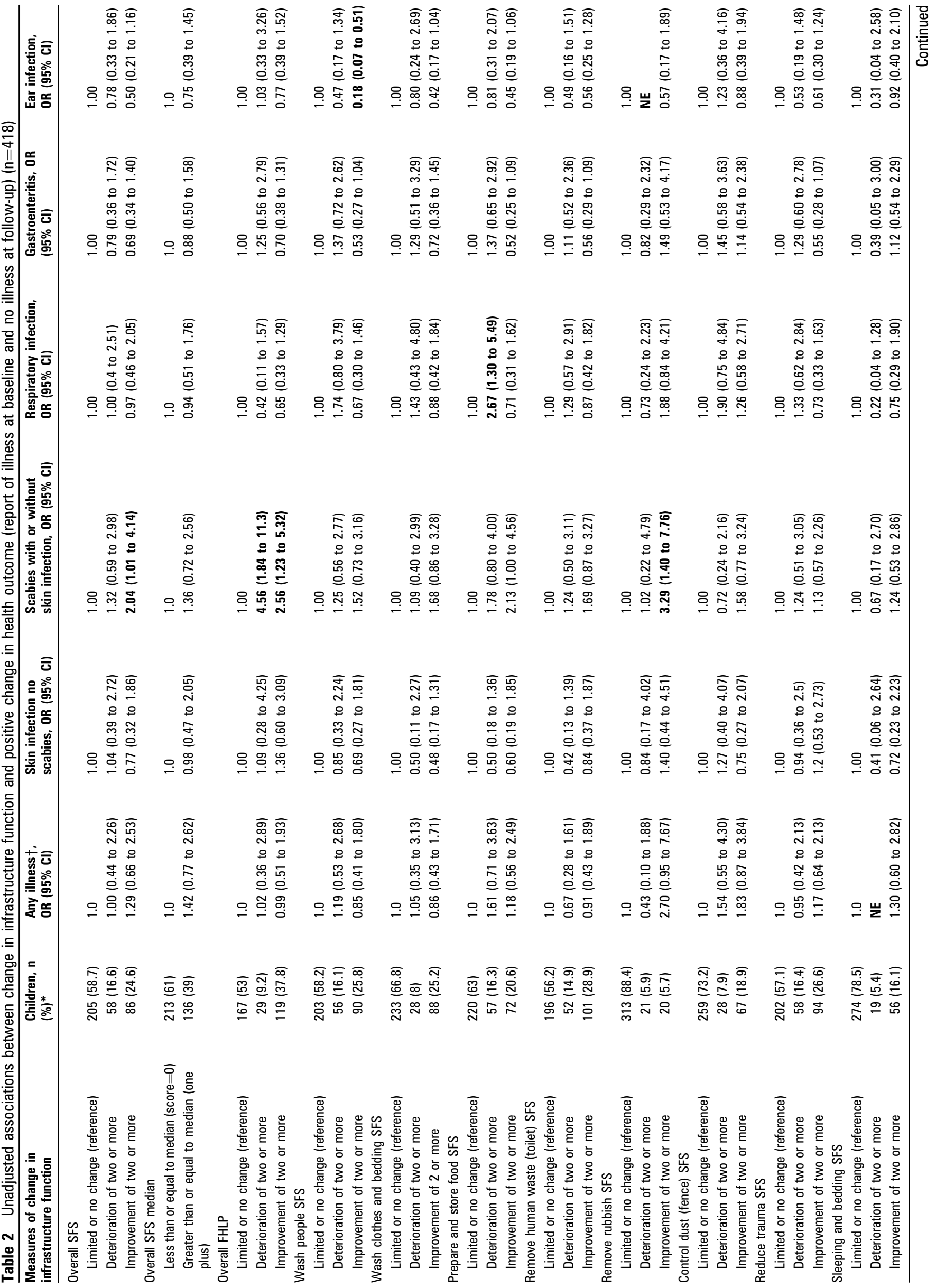




\section{Research report}

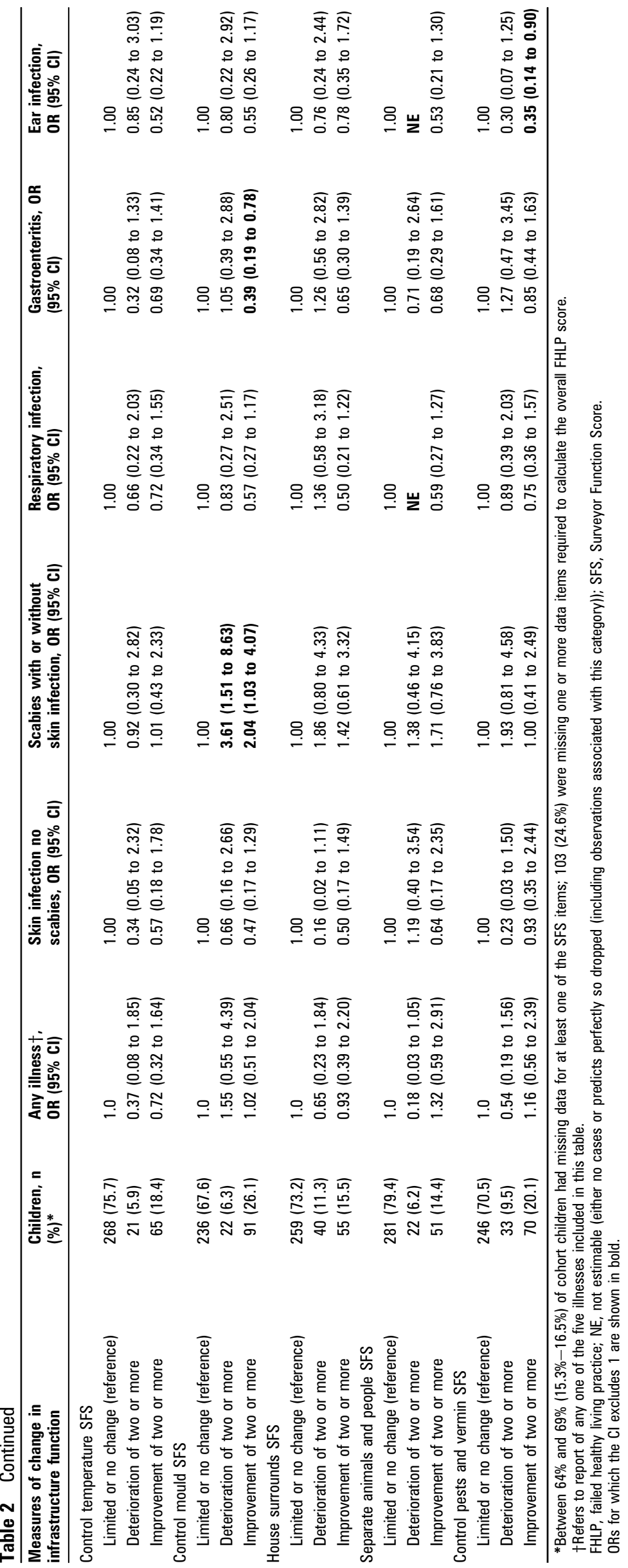


follow-up; for $12 \%$ of children, there was a reduction in PPB of two or more, while for $27 \%$, there was an increase in PPB of two or more; for $31 \%$, there was a reduction of two or more adults in the house, while for $17 \%$, there was an increase in two or more adults in the house (see supplementary file 1: table 1a); for $12 \%$ of children where the telephone and/or refrigerator were not working at baseline, both were working at follow-up (see supplementary file 1 : table $1 \mathrm{~b}$ ); for $10 \%-17 \%$ of children, there was an increase in the number of negative life events reported by their carer; for $11 \%$ of children where the carer's score on the Brief Screen for Depression Scale at baseline did not indicate depression, the score at follow-up was in the high-risk range (see supplementary file 1: table 1c); for $16 \%$ of children, there was a broom, mop and bucket in the house where at least one of these items had been missing at baseline; for 18\% of children, there was soap in the bathroom, kitchen or laundry where there had been none at baseline; for about $20 \%$, there was a decrease of two or more in the number of people who smoked indoors, while for $22 \%$, there was an increase of two or more; for $24 \%$ of children, there was a deterioration in the hygiene condition score (SCS) of two or more points, while for $20 \%$, there was an improvement of two or more points (see supplementary file 1 : table 1d). For all other secondary exposures, there was a change in exposure category between baseline and follow-up for $<10 \%$ of children.

\section{Unadjusted bivariate associations for logistic regression analysis of primary outcome and secondary exposure variables} A number of sociodemographic variables were associated with positive change in one or more of the health outcomes, including child age at baseline, change in child mobility, change in child day care attendance, reduction in crowding (as measured by PPB and by number of adults in dwelling), number of adults in dwelling at baseline and change in child relationship to householder (see supplementary file 1: table 1a). There were no significant associations between socio-economic status and financial stress variables or carer psychosocial variables and positive change in health outcomes (see supplementary file 1: tables $1 \mathrm{~b}$ and $1 \mathrm{c}$ ).

Among the health-related behaviour variables, increased availability of household cleaning equipment (broom/mop/ bucket) was associated with a positive change in report of gastroenteritis, and a history of breast feeding was associated with a positive change in report of respiratory infection (see supplementary file 1: table 1d). Where there was deterioration in the overall hygienic condition of the house (overall SCS measure), there was less likely to be a report of positive change in respiratory infection. A number of measures of hygienic state of specific components of household infrastructure also showed significant associations with positive change in health outcomes, some in the expected direction and some in the opposite direction (see supplementary file 1 : table 1d).

\section{Associations between change in infrastructure function, hygienic condition and crowding}

In order to shed light on the possible causal relationships between the important variables of improvement in infrastructure, crowding and household hygiene that we have previously reported on at the community level, ${ }^{19}$ we examined relationships between these variables at the individual child level. Children living in houses that had a deterioration in infrastructure function (SFS) were more likely to have a deterioration in the hygienic condition of the house (SCS) (relative risk ratio (RRR 4.79, 95\% CI 1.66-13.8), and children in houses that had
Table 3 Associations between change in house infrastructure function (overall SFS), change in hygienic condition (overall SCS) and change in crowding (PPB) using multinomial logit regression models

\begin{tabular}{|c|c|}
\hline Dependent variable & $\operatorname{RRR}(95 \%$ CI) \\
\hline \multicolumn{2}{|l|}{ SFS change in overall house } \\
\hline \multicolumn{2}{|l|}{ SFS deterioration two or more } \\
\hline SCS limited or no change & 1.0 \\
\hline SCS deterioration two or more & 4.79 (1.66 to 13.8$)$ \\
\hline SCS improvement two or more & $1.98(0.39$ to 10.1$)$ \\
\hline \multicolumn{2}{|l|}{ SFS improvement two or more } \\
\hline SCS limited or no change & 1.0 \\
\hline SCS deterioration two or more & $0.63(0.20$ to 1.96$)$ \\
\hline SCS improvement two or more & $3.93(1.62$ to 9.54$)$ \\
\hline Pseudo adjusted $\mathrm{R}^{2 *}$ & $8.1 \%$ \\
\hline
\end{tabular}

SFS change in overall house

SFS deterioration two or more

PPB limited or no change

$P P B \geq 1$ decrease

1.0

$\mathrm{PPB} \geq 1$ increase

$0.60(0.15$ to 2.33$)$

$0.86(0.26$ to 2.89$)$

SFS improvement two or more

PPB limited or no change

1.0

$\mathrm{PPB} \geq 1$ decrease

2.37 (0.99 to 5.68$)$

$P P B \geq 1$ increase

Pseudo adjusted $\mathrm{R}^{2 *}$

$0.46(0.12$ to 1.81$)$

$1.1 \%$

Change in PPB

$\mathrm{PPB} \geq 1$ decrease

SCS limited or no change

1.0

SCS deterioration two or more

0.51 (0.17 to 1.58 )

SCS improvement two or more

1.01 (0.38 to 2.71$)$

$\mathrm{PPB} \geq 1$ increase

SCS limited or no change

1.0

SCS deterioration two or more $\quad 1.39(0.48$ to 4.00$)$

SCS improvement two or more $\quad 1.19(0.35$ to 4.12$)$

Pseudo adjusted $\mathrm{R}^{2 *}$

$1.2 \%$

*Reference category (dependent and independent variables) for these models is limited or no change (for SFS and SCS limited or no change $=$ change of $<2$ points; and for PPB limited or no change $=$ change of $<1 \mathrm{PPB}$ ).

PPB, persons per bedroom; RRR, relative risk ratios; SCS, Surveyor Condition Score; SFS, Surveyor Function Score.

ORs for which the $\mathrm{Cl}$ excludes 1 are shown in bold.

an improvement in infrastructure function (SFS) were more likely to have improvement in hygienic condition of the house (SCS) (RRR 3.93, 95\% CI 1.62-9.54) (table 3). The model testing for an association between change in SFS and change in PPB was marginally non-significant and indicates that for children living in houses that had an improvement in SFS, there also tended to be a decrease in crowding (RRR 2.37, 95\% CI 0.99-5.68). There was no significant association between change in PPB and change in SCS.

\section{Multivariate logistic regression analysis of association between primary outcome measures and primary and secondary exposure variables}

After adjustment for secondary exposure variables in logistic regression models, there were no significant positive associations between improved household infrastructure (including overall SFS) and positive change health outcomes for report of any illness, scabies, skin infection, respiratory infection and gastroenteritis or ear infection (table 4). On the contrary, there were a number of significant counterintuitive associations 
Table 4 Adjusted associations between exposure variables (primary and secondary) and positive change in health outcome (report of illness at baseline and no report at follow-up)

\begin{tabular}{|c|c|c|c|c|c|c|}
\hline Explanatory variables & $\begin{array}{l}\text { Any illness* } \\
(\mathrm{n}=354 / 418) \\
\text { OR }(95 \% \mathrm{CI})\end{array}$ & $\begin{array}{l}\text { Skin infection } \\
\text { (no scabies) } \\
\text { (n=302/418) } \\
\text { OR }(95 \% \text { Cl) }\end{array}$ & $\begin{array}{l}\text { Scabies with or } \\
\text { without skin infection) } \\
\text { ( } \mathrm{n}=315 / 418) \\
\text { OR }(95 \% \mathrm{Cl})\end{array}$ & $\begin{array}{l}\text { Respiratory } \\
\text { infection } \\
(\mathrm{n}=349 / 418) \\
\text { OR }(95 \% \mathrm{CI})\end{array}$ & $\begin{array}{l}\text { Gastroenteritis } \\
(\mathrm{n}=331 / 418) \\
\text { OR }(95 \% \text { Cl) }\end{array}$ & $\begin{array}{l}\text { Ear infection } \\
(n=349 / 418) \\
O R(95 \% \mathrm{Cl})\end{array}$ \\
\hline \multicolumn{7}{|l|}{ Primary exposure } \\
\hline \multicolumn{7}{|l|}{ Change in overall FHLP } \\
\hline Limited or no change & - & - & 1.00 & - & - & - \\
\hline Deterioration of two or more & - & - & $4.23(1.66$ to 10.8$)$ & - & - & - \\
\hline Improvement of two or more & - & - & 2.18 (0.96 to 4.97$)$ & - & - & - \\
\hline \multicolumn{7}{|l|}{ Change in wash people SFS } \\
\hline Limited or no change & - & - & - & - & - & 1.0 \\
\hline Deterioration of two or more & - & - & - & - & - & $0.47(0.17$ to 1.34$)$ \\
\hline Improvement of two or more & - & - & - & - & - & $0.18(0.07$ to 0.51 \\
\hline \multicolumn{7}{|c|}{ Change in prepare and store food SFS } \\
\hline Limited or no change & - & - & - & 1.0 & - & - \\
\hline Deterioration of two or more & - & - & - & $3.31(1.56$ to 6.89$)$ & - & - \\
\hline Improvement of two or more & - & - & - & $1.02(0.39$ to 2.65$)$ & - & - \\
\hline \multicolumn{7}{|l|}{ Change in control mould SFS } \\
\hline Limited or no change & - & - & - & - & 1.0 & - \\
\hline Deterioration of two or more & - & - & - & - & $1.07(0.43$ to 2.65$)$ & - \\
\hline Improvement of two or more & - & - & - & - & $0.33(0.14$ to 0.77$)$ & - \\
\hline \multicolumn{7}{|l|}{ Secondary exposure variables } \\
\hline Change in PPB & & NS $(p=0.28)$ & & & & \\
\hline Limited change & - & 1.00 & - & - & - & - \\
\hline Reduction of $\geq 2$ PPB & - & $1.81(0.82-4.02)$ & - & - & - & - \\
\hline Increase of $\geq 2 \mathrm{PPB}$ & - & $0.71(0.16$ to 3.11$)$ & - & - & - & - \\
\hline \multicolumn{7}{|l|}{ Overall house SCS } \\
\hline Limited or no change & - & - & - & 1.0 & - & - \\
\hline Deterioration of two or more & - & - & - & $0.21(0.09$ to 0.51$)$ & - & - \\
\hline Improvement of two or more & - & - & - & $0.86(0.40$ to 1.89$)$ & - & - \\
\hline \multicolumn{7}{|l|}{ Wash people SCS } \\
\hline Limited or no change & - & - & - & 1.0 & - & - \\
\hline Deterioration of two or more & - & - & - & $1.58(0.66$ to 3.81$)$ & - & - \\
\hline Improvement of two or more & - & - & - & $0.33(0.12$ to 0.90$)$ & - & - \\
\hline \multicolumn{7}{|l|}{ Control dust SCS } \\
\hline Limited or no change & - & - & 1.00 & - & - & - \\
\hline Deterioration of two or more & - & - & $2.30(0.96$ to 5.54$)$ & - & - & - \\
\hline Improvement of two or more & - & - & $2.33(0.94$ to 5.77$)$ & - & - & - \\
\hline \multicolumn{7}{|c|}{ Separate animals and humans SCS } \\
\hline Limited or no change & 1.0 & - & - & - & 1.0 & - \\
\hline Deterioration of two or more & $0.48(0.18$ to 1.33$)$ & - & - & - & $1.01(0.42$ to 2.42$)$ & - \\
\hline Improvement of two or more & $4.01(2.12$ to 7.57$)$ & - & - & - & $3.68(1.59$ to 8.55$)$ & - \\
\hline \multicolumn{7}{|l|}{ Day care attendance change } \\
\hline No change & - & - & - & - & 1.0 & - \\
\hline Change from no to yes & - & - & - & - & $2.40(1.14$ to 5.02$)$ & - \\
\hline Change from yes to no & - & - & - & - & $3.84(1.29$ to 11.5$)$ & - \\
\hline Adjusted $\mathrm{R}^{2}$ & $6.3 \%$ & $1.3 \%$ & $6.8 \%$ & $8.9 \%$ & $8.9 \%$ & $5.2 \%$ \\
\hline
\end{tabular}

Adjusted using hierarchical multivariate logistic regression models. Only statistically significant associations are shown. ORs $>1$ indicate a higher likelihood of a positive change in health outcome and $\mathrm{ORs}<1$ indicate a lower likelihood of a positive change in health outcome.

* Refers to report of any one of the five illnesses included in this table.

FHLP, failed healthy living practice; PPB, persons per bedroom; RRR, relative risk ratios; SCS, Surveyor Condition Score; SFS, Surveyor Function Score.

ORs for which the $\mathrm{Cl}$ excludes 1 are shown in bold.

between measures of change in infrastructure function and positive change health outcomes on carer report of various illnesses.

Among the secondary exposure variables, improvement in the 'separate animals and humans' SCS was significantly associated with positive change in report of any illness, gastroenteritis and ear infection. Reduction in crowding was associated with a positive change in report of skin infection. Deterioration in overall SCS was negatively associated with a positive change health outcome for respiratory infection.
Counterintuitively, improvement in 'wash people' SCS was negatively associated with positive change in report of respiratory infection, and change in childcare attendance (either from attending at baseline to not attending at follow-up or vice versa) was associated with positive change in report of gastroenteritis.

Given the evidence from the stratified analysis that the relationship between improvement in infrastructure and child health outcomes may be modified by changes in crowding, we examined interactions between level of change in crowding and 
each of the variables which showed a significant association with each of the child health outcome measures in the multivariate analysis reported above (see supplementary file 3). For multivariate models examining associations with positive change health outcome in carer report of gastroenteritis (see supplementary file 3 : table $3 \mathrm{~d}$ ) and of respiratory infection (see supplementary file 3: table 3c), the addition of these interaction terms increased the explanatory power of the model (as reflected in the adjusted $\mathrm{R}^{2}$ ). For models for carer report of gastroenteritis, the effects were generally consistent with the expected direction of effect modification, but this was not the case for carer report of respiratory infection. The addition of interaction terms to models for carer report of any illness, scabies and ear infection did not increase the explanatory power of the models.

\section{DISCUSSION}

The building programs in the 10 communities that were the subject of the study have not resulted in a consistent reduction in carers' reporting of common childhood illnesses, either for specific illnesses or for these illnesses in general. There is also no consistent evidence that, in the circumstances of these communities at the time of this study, there are specific factors (such as levels or changes in household crowding or hygienic conditions), which modify the potential effect of improved household infrastructure.

While our main findings are consistent with other Australian and international evidence that infrastructure improvements alone have limited potential to improve health, ${ }^{2-8}$ they contrast with those of a recent evaluation of a housing program in Aboriginal communities in the state of New South Wales (NSW) which showed a reduction in hospital admissions for children with various infectious conditions. ${ }^{33}$ However, the ecological design and lack of adjustment for potential confounders in the NSW evaluation limits the ability to attribute causality from these findings. In addition to lack of control for confounding factors in the NSW study, reasons for differences between the NSW study and our study include (1) the average number of people per house in the NSW communities (4.1) was substantially less than in the communities in our study (11) and (2) that the NSW study outcomes used hospital admissions, while we examined carer report of illness. It is possible that housing improvements may have an effect on more severe illness and not on carer report of illness. However, analysis of data from the $\mathrm{HICH}$ Study on the association between change in health centre presentations and improved housing conditions produced similar results to the data on carer report of childhood illness presented in this paper. The use of data on health service presentations for multisite and longitudinal studies is subject to important limitations resulting from differences in access to and use of primary healthcare centres in different communities, the quality of clinical records in these health centres and variation over time in access to care and quality of documentation as a result of staff turnover and variation in staff capacity. It is for these reasons that we have focused on career report of illness as our preferred method of assessing impact of improved housing conditions on common childhood illness. Alternative approaches such as standardised regular clinical examination were excluded on the basis of resource constraints.

Importantly, individual children who experienced an improvement in infrastructure were about four times more likely to experience an improvement in hygienic conditions. Conversely, children who experienced deterioration in infrastructure were about five times more likely to experience deterioration in hygienic conditions. However, as reported previously, ${ }^{19}$ there was no clear overall improvement in household hygiene at a community level as a result of the building programs. Furthermore, the analysis presented in this paper shows that individual children who experienced an improvement in infrastructure were not (or only marginally) more likely to also experience an improvement in household crowding. At the community level, the impact of the building programs on crowding was also small (3.4 PPB to $3.2 \mathrm{PPB}) .{ }^{19}$ In the context of the wide recognition that high levels of crowding facilitate the transmission of infectious disease, the results of our analysis indicate that the ongoing high levels of crowding and the generally poor levels of household hygiene in these communities are likely to be important factors in the apparent failure of the building programs to impact on common childhood illnesses. High levels of interaction between children in the community and mobility of children between houses mean that conditions across the community in general are likely to be at least as important as household conditions for individual children in influencing the spread of infectious diseases. The continuing and pervasive poor social, financial and employment conditions, whether these are associated with traditional beliefs or other social factors, and the lack of concurrent effective programs to address these factors are also likely to limit the potential for building programs to impact on the health of residents in these communities.

The evidence that improvement in other household factors is associated with significant improvements in child health provides important information for further development of housing and complementary health improvement programs in this environment and for guiding further research. Our study provides some evidence that improvement in hygienic conditions, such as the effective separation of animals and humans, has the potential to result in reduction in various infectious conditions for children in these communities (table 4). A wide range of infectious diseases in humans are associated with interactions between humans and animals, and various hygiene measures are recommended to prevent such infections (such as hand washing, safe disposal of animal faeces and exclusion of animals from areas where food is prepared or consumed). ${ }^{34}$

We have previously described the strength of the HICH Study in terms of: (1) the measurement and assessment of the concurrent influence of a range of other related factors with the potential to confound or modify the association between housing condition and health and the statistical adjustment to assess the influence of such factors; (2) the value of measuring a range of important exposures as well as a range of outcomes ${ }^{17}$ (3) the detailed assessment of the functional state of a wide range of items of housing infrastructure and of the hygienic condition of the household environment and (4) the inclusion of multiple communities spread across a wide geographic area in order to enhance the potential generalisability of the findings, at least within the context of remote Australian Aboriginal communities. ${ }^{17}$ In addition, the cohort analysis presented here provides stronger evidence of causal relationships than our previous report of cross-sectional analysis of baseline data. ${ }^{17}$ Follow-up analysis of data on individual children complements community-level analysis, including specifically on the important issues of crowding and household hygienic condition.

As reported previously, ${ }^{17}{ }^{19}$ limitations of the study include (1) the difficulty of defining and measuring appropriate indicators for the range of complex constructs inherent in the study conceptual framework; (2) the potential for respondent and recall bias associated with reliance on interview data for outcome and secondary exposure and confounding variables; (3) the potential 


\section{What is already known on this subject}

Elements of the household and community environment are important underlying determinants of the occurrence of the common childhood conditions, which impair child growth and development and contribute risk for chronic disease. However, there is a lack of good research evidence on the impact of housing programs on the occurrence of these common childhood infections.

\section{What this study adds}

The study adds to the strength of the evidence that house infrastructure improvement programs which do not reduce high levels of crowding and which are not accompanied by programs to improve the general community environment or health-related behaviour are unlikely to reduce the occurrence of common childhood infections.

for chance associations in analyses involving large numbers of variables (although chance associations are limited by the use of hierarchical models and a focus on identifying consistent associations between exposure measures and a number of different health outcomes); (4) the potential for measurement error/ misclassification, particularly in relation to the possibility of the state of hygiene at the time of the survey not being a fair reflection of the state of hygiene over a longer period of time (although repeatability of most SCS measures was shown to be reasonably high over a period of a few weeks ${ }^{17}$ ); (5) the potential for ORs to overestimate the strength of associations for high prevalence exposures and (6) variation in the time between the surveys and the occupation of new houses. In addition, there was some loss to follow-up of children who were included in the baseline survey, and we were not able to get complete data for children who were followed up (figure 1). However, there was little difference between children in the cohort compared with those lost to follow-up across a range of variables.

The evidence of exceptionally high levels of household crowding and of the association between crowding and child health point to the need for housing programs to be massively scaled-up with a stronger population-based approach and an emphasis on achieving adequate standards of housing infrastructure for as many people as possible. Recent media reports highlight the inadequacy of investment to build the required number of houses (and houses with adequate numbers of bedrooms) and the failure of effective implementation of funded housing programs. ${ }^{35-37}$ However, there continues to be a relative lack of attention to the requirement for concurrent health (and hygiene) promotion programs despite consistent evidence on the effectiveness of some hygiene interventions (such as hand washing) in reducing rates of infectious disease.

\section{CONCLUSION}

Our findings add to the mounting evidence which point to the need for building programs to be supported by a range of other social, behavioural and community-wide environmental interventions in order for the potential health gains of improved housing to be more fully realised. ${ }^{17} 1938-40$
Acknowledgements We wish to acknowledge the hard work and commitment of project and fieldwork officers Phil O'Donohoe (dec.), Kat Lonergan, Harold Ulamari, Emma Kowal and Kayli Wayte, and the expert advice of Professor David Brewster and Steve Guthridge. The participation of community residents and the assistance of the Indigenous Housing Association of the NT (IHANT), Community Housing and Community Council Officers is greatly appreciated.

Funding National Health and Medical Research Council (NHMRC) Project grant number 236205. The Co-operative Research Centre for Aboriginal Health (CRCAH). RSB's work in this area is supported by a National Health and Medical Research Centre Senior Research Fellowship number 283303. ELM is supported by a National Health and Medical Research Centre-Aboriginal and Torres Strait Islander Training Fellowship.

\section{Competing interests None}

\section{Patient consent Obtained.}

Ethics approval This study was conducted with the approval of the Human Research Ethics Committees in the Top End and Central regions of the Northern Territory, Australia.

Provenance and peer review Not commissioned; externally peer reviewed.

\section{REFERENCES}

1. Wright J, Gundry S, Conroy R. Household drinking water in developing countries: a systematic review of microbiological contamination between source and point-ofuse. Trop Med Int Health 2004;9:106-17.

2. Black M. Learning What Works: A 20 Year Retrospective View on International Water and Sanitation Cooperation. Washington, DC: UNDP-World Bank Water and Sanitation Program, 1998.

3. de Bruijne G, Geurts M, Appleton B. Sanitation for All? 2007. http://http://www.irc. nl/page/36722 (accessed 12 2010)

4. Long J. Settlement: a history of Australian Indigenous housing. In: Read P, ed. The Commonwealth Government and Aboriginal Housing, 1968-1981. Canberra: Aboriginal Studies Press, 2000:103-17.

5. Bailie RS, Wayte KJ. Housing and health in Indigenous communities: key issues for housing and health improvement in remote Aboriginal and Torres Strait Islander communities. Aust J Rural Health 2006;14:178-83.

6. McDonald E, Bailie R, Brewster D, et al. Are hygiene and public health interventions likely to improve outcomes for Australian Aboriginal children living in remote communities? A systematic review of the literature. BMC Public Health 2008;8:153.

7. Cairnduff S, Guthridge S. Exploring Indigenous Home Management Programs in the Northern Territory. 2002. http://www.lowitja.org.au/files/crcah docs/Exploring Indigenous_Home.pdf (accessed 12 Jun 2011).

8. Tatz C. Innovation without change. In: Hetzel B, ed. Health Services for Aborigines. Brisbane: University of Queensland, 1974:107-20.

9. NATSIH Council. National Strategic Framework for Aboriginal and Torres Strait Islander Health: Framework for Action by Governments. 2003. http://www.health.gov. au/internet/main/publishing.nsf/Content/14AFC82C99F3E206CA257474001E6E75/ \$File/nsfatsihfinal.pdf (accessed 12 2010).

10. Shaw M. Housing and public health. Annu Rev Public Health 2004;25:397-418.

11. Krieger J, Higgins DL. Housing and health: time again for public health action. $A m \mathrm{~J}$ Public Health 2002;92:758-68.

12. Fuller-Thomson $\mathbf{E}$, Hulchanski JD, Hwang $S$. The housing/health relationship: what do we know? Rev Environ Health 2000;15:109-33.

13. Wilkinson D. Poor Housing and III Health: A Summary of Research Evidence. 1999. http://www.scotland.gov.uk/Resource/Doc/156479/0042008.pdf laccessed 12 2010).

14. Moloughney B. Housing and Population Health-The State of Current Research Knowledge. 2004. http://www.secure.cihi.ca/cihiweb/products/HousingPopHealth_e. pdf (accessed 12 2010)

15. Thomson H, Petticrew M, Morrison D. Health effects of housing improvement: systematic review of intervention studies. BMJ 2001;323:187-90.

16. Dockery AM, Kendall G, Li J, et al. Housing and Children's Development and Well-being: A Scoping Study. 2010. http://www.healthbulletin.org.au/articles/ housing-and-childrens-development-and-wellbeing-a-scoping-study laccessed 12 2010).

17. Bailie R, Stevens M, McDonald E, et al. Exploring cross-sectional associations between common childhood illness, housing and social conditions in remote Australian Aboriginal communities. BMC Public Health 2010;10:147.

18. Bailie RS, Stevens MR, McDonald E, et al. Skin infection, housing and social circumstances in children living in remote indigenous communities: testing conceptual and methodological approaches. BMC Public Health 2005;5:128.

19. Bailie RS, McDonald EL, Stevens M, et al. Evaluation of an Australian indigenous housing programme: community level impact on crowding, infrastructure function and hygiene. J Epidemiol Community Health 2011;65:432-7. [Epub ahead of print: 11 Aug 2010].

20. McDonald E, Bailie R, Morris P, et al. Interventions to Prevent Growth Faltering in Remote Indigenous Communities. 2006. http://www.anu.edu.au/aphcri/Domain/ ATSIPHC/Final_25_Bailie.pdf (accessed 12 2010). 
21. Li S, Guthridge S, d'Espaignet E, et al. From Infancy to Young Adulthood: Health Status in the Northern Territory 2006. http://www.digitallibrary.health.nt.gov.au/ dspace/bitstream/10137/84/1/infancy_to_young_adulthood_2006.pdf (accessed 12 2010).

22. Coates HL, Morris PS, Leach AJ, et al. Otitis media in Aboriginal children: tackling a major health problem. Med J Aust 2002;177:177-8.

23. Brewster D. Failure to thrive. In: Couzos S, Murray R, eds. Aboriginal Primary HealthCare: An Evidence-Based Approach. 2nd edn. Melbourne: Oxford University Press, 2003:162-85

24. Chang AB, Grimwood K, Mulholland EK, et al. Bronchiectasis in indigenous children in remote Australian communities. Med J Aust 2002;177:200-4.

25. Carapetis JR, Walker AM, Hibble M, et al. Clinical and epidemiological features of group A streptococcal bacteraemia in a region with hyperendemic superficial streptococcal infection. Epidemiol Infect 1999;122:59-65.

26. Carapetis JR, Currie BJ, Kaplan EL. Epidemiology and prevention of group A streptococcal infections: acute respiratory tract infections, skin infections, and their sequelae at the close of the twentieth century. Clin Infect Dis 1999;28:205-10.

27. Leach AJ. Otitis media in Australian Aboriginal children: an overview. Int $J$ Pediatr Otorhinolaryngol 1999:49:S173-S8.

28. ABS/AIHW. The Health and Welfare of Australia's Aboriginal and Torres Strait Islander Peoples. 2008. http://www.aihw.gov.au/publications/index.cfm/title/10583 (accessed 12 2010).

29. Saegert SC, Klitzman S, Freudenberg N, et al. Healthy housing: a structured review of published evaluations of US interventions to improve health by modifying housing in the United States, 1990-2001. Am J Public Health 2003:93:1471-7.

30. Kowal E, Donohoe P, Lonergan $K$, et al. Dust, distance and discussion: fieldwork experiences from the housing improvement and child health study. Environ Health 2005;5:59-72.
31. Pholeros P, Rainow S, Torzillo P. Housing for Health-Towards a Healthy Living Environment for Aboriginal Australia. Newport Beach, NSW: Health Habitat, 1993.

32. Department of Families, Housing, Community Services and Indigenous

Affairs. National Indigenous Housing Guide: Improving the living environment for safety, health and sustainability. Commonwealth of Australia, 2008. http://www. fahcsia.gov.au/sa/indigenous/progserv/housing/Documents/default.htm laccessed 12 Jun 2011)

33. Aboriginal Environmental Health Unit. Closing the Gap: 10 Years of Housing for Health in NSW. An Evaluation of a Healthy Housing Intervention. 2010. http://www. whitetail.dmz.health.nsw.gov.au/pubs/2010/pdf/housing_health_010210.pdf (accessed 12 2010).

34. NASPHV. Compendium of Measures to Prevent Disease Associated with Animals in Public Settings. 2009. http://www.cdc.gov/mmwr/preview/mmwrhtml/rr5805a1.htm laccessed 12 Jun 2011).

35. Russell L. Commonwealth Indigenous Budget Bulletin. 2010. http://www. macroeconomics.com.au/files/Commonwealth_Indigenous_Budget_Bulletin_July_ 2010.pdf (accessed 12 2010).

36. Karvelas P. Half of Homes Funds Lost to Administration. The Australian Newspaper 2011. http://www.theaustralian.com.au/national-affairs/half-of-homes-funds-lost-toadmin/story-fn59niix-1225991357418 (accessed 12 Jun 2011)

37. Henderson A. Housing Program Won't Increase Houses: CLP. 2010. http://www. abc.net.au/news/stories/2010/11/19/3071354.htm (accessed 12 Jun 2011).

38. Cairncross S, Curtis V. Hygiene and Sanitation Promotion. Geneva: Water Supply and Sanitation Collaborative Council, 2002

39. Ejemot RI, Ehiri JE, Meremikwu MM, et al. Hand washing for preventing diarrhoea Cochrane Database Syst Rev 2008:(1):CD004265.

40. Storti C. The Hygiene Improvement Framework: A Comprehensive Approach for Preventing Childhood Diarrhea. 2004. http://www.ehproject.org/PDF/ Joint_Publications/JP008-HIF.pdf (accessed 12 2010). 